\title{
Simulasi Ketinggian dan Waktu Tiba Gelombang Tsunami di Tahuna Sebagai Upaya Mitigasi Bencana
}

\author{
Brian Mambua*, Gerald H. Tamuntuana, Guntur Pasaua \\ aJurusan Fisika, FMIPA, Unsrat, Manado
}

KATA K U N C I

Tsunami, Tahuna, mitigasi

KEYW OR D S

tsunami, Tahuna, mitigation

\begin{abstract}
A B S T R A K
Indonesia merupakan salah satu wilayah rawan bencana gempa bumi dan tsunami. Wilayah beresiko tinggi terjadi gempa bumi dan tsunami berada di laut Sulawesi dimana terdapat zona subduksi Sulawesi Utara. Salah satu cara mitigasi tsunami adalah dengan mensimulasikan ketinggian dan waktu tiba gelombang tsunami. Karena berada di wilayah laut Sulawesi maka Tahuna beresiko mengalami bencana tsunami. Pemodelan gelombang tsunami menggunakan software TUNAMI-N2. Hasil yang didapatkan menunjukkan bahwa, ketinggian gelombang yang dapat menerjang Tahuna adalah 0,23 m dengan waktu tiba sekitar menit ke-50.
\end{abstract}

TERSEDIA ONLINE 01 Februari 2019

\section{Pendahuluan}

Indonesia merupakan wilayah rawan bencana gempa bumi yang berpotensi tsunami. Hal ini diakibatkan terdapat banyak zona pertemuan antar lempeng yang berada di wilayah Indonesia. Salah satu wilayah Indonesia dengan aktivitas kegempaan yang tinggi yaitu Sulawesi Utara. Gempa bumi di Sulawesi Utara disebabkan oleh Zona Subduksi Sulawesi Utara dan Zona Subduksi Ganda Laut Maluku.

Zona Subduksi Sulawesi Utara terdapat di Laut Sulawesi di sebelah utara Pulau Sulawesi. Zona subduksi ini terjadi akibat tumbukan antara lempengan Laut Sulawesi dan lempengan lengan utara Pulau Sulawesi dan dapat mengakibatkan gempa dengan magnitudo maksimum 8,0 (Pasau dan Tanauma, 2011).

Perpecahan disepanjang garis patahan aktif di mana dua bagian dari kerak bumi bergerak berlawanan arah menyebabkan gempa bumi pembangkit tsunami. Gempa bumi yang dapat membangkitkan tsunami memiliki magnitudo sebesar 6,5 SR dengan kedalaman $10 \mathrm{~km}$ dan dapat dibangkitkan oleh patahan dip-slip, thrust-dip, dan strike-slip. Dari ketiganya, patahan dip-slip yang paling ideal dalam membangkitkan tsunami besar (Bryant, 2014).

Menurut Hamzah (2000), wilayah Laut Sulawesi masuk dalam zona E sebagai wilayah yang rawan terjadi tsunami dimana dalam rentang 398 tahun telah terjadi gempa bumi yang diikuti tsunami sebanyak 32 kali yang memakan korban hingga 7.576 jiwa. Tsunami adalah gelombang yang dibangkitkan oleh pergerakan vertikal dari kolom air. Pergerakan ini dapat disebabkan oleh aktivitas seismik, letusan gunung api, longsoran di dasar atau di atas laut, tubrukan benda langit, atau fenomena meteorologi. Mayoritas tsunami dibangkitkan oleh aktivitas seismik di bawah laut. Lebih dari dua abad yang lalu, gempa bumi telah

*Corresponding author: Jurusan FisikaFMIPA UNSRAT, Jl. Kampus Unsrat, Manado, Indonesia 95115; Email address: zmam411@gmail.com 
menghasilkan 83\% dari semua tsunami di Samudra Pasifik (Bryant, 2014).

Upaya penanggulangan bencana tsunami dapat dilakukan dengan melakukan simulasi di daerah yang berpotensi mengalami tsunami (Lovholt et al, 2012). Salah satu software yang dapat digunakan adalah TUNAMI-N2 (Imamura et al., 2006). Software ini pernah dipakai untuk mensimulasikan penjalaran tsunami di beberapa tempat di berbagai belahan dunia yang rawan tsunami (Fu et al, 2017; Heidarzadeh dan Satake, 2017; Selvan dan Kankara, 2016; Pribadi et al., 2016; Prerna et al., 2014). Software ini dapat digunakan untuk menentukan ketinggian dan waktu tiba gelombang tsunami.

Salah satu yang berpotensi mengalami gempa bumi dan tsunami adalah Tahuna di Kepulauan Sangihe karena masih berada di wilayah Laut Sulawesi. Oleh karena itu, penting dilakukan upaya mitigasi bencana di daerah tersebut dengan mensimulasikan ketinggian dan waktu tiba gelombang tsunami.

\section{Material dan Metode}

Data yang dibutuhkan dalam penelitian ini adalah data bathymetri dan data patahan gempa bumi yang akan digunakan sebagai nilai masukan pada software TUNAMI-N2. Data bathymetri didapatkan dari GEBCO (General Bathymetric Chart of Ocean). Penelitian ini menggunakan gempa bumi dengan magnitudo 8,0 SR pada koordinat $121,558^{\circ}$ BT dan 2,297० LU yang berada di Laut Sulawesi. Magnitudo gempa bumi kemudian diolah menggunakan persamaan Wells dan Coppersmith (1994) untuk mendapatkan nilai panjand dan lebar dari sesar yang akan memicu gelombang tsunami.

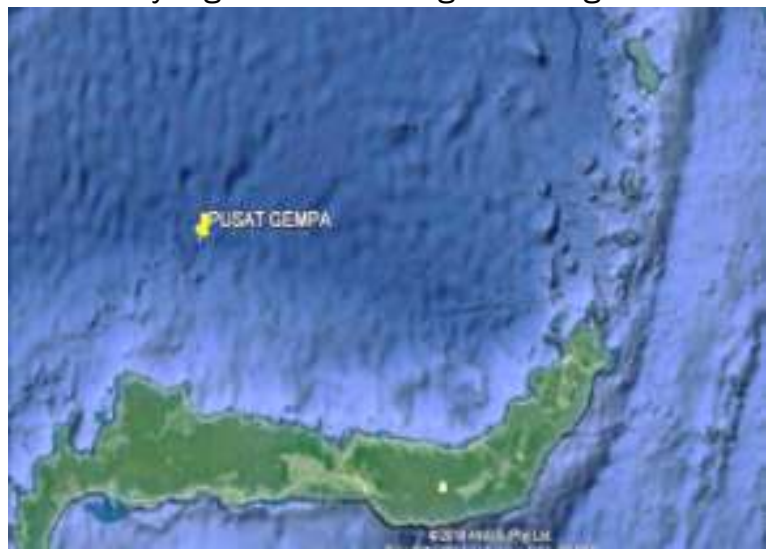

Gambar 1. Lokasi Pusat Gempa

Kemudian pada software GMT (General Mapping Tools) dibuat 3 layer yang mengelilingi daerah yang akan menjadi pusat penelitian. Semakin kecil ukuran dari layer semakin besar tingkat akurasi dari data.

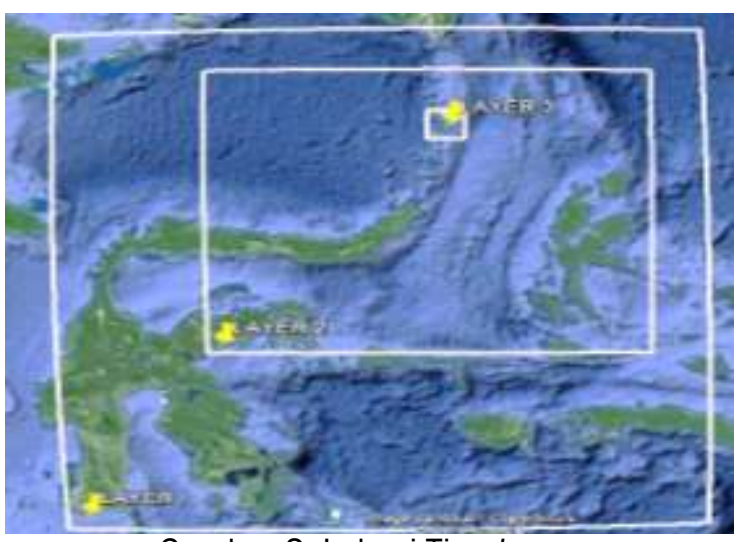

Gambar 2. Lokasi Tiap Layer

Nilai ketinggian dan waktu tiba dari gelombang tsunami didapatkan dengan menempatkan titik imajiner pada software TUNAMI-N2 yang disebut dengan Tide Gauge. Titik ini ditempatkan didepan Tahuna. Data dari tide gauge kemudian akan ditampilkan dalam bentuk grafik dengan program MS Excel.

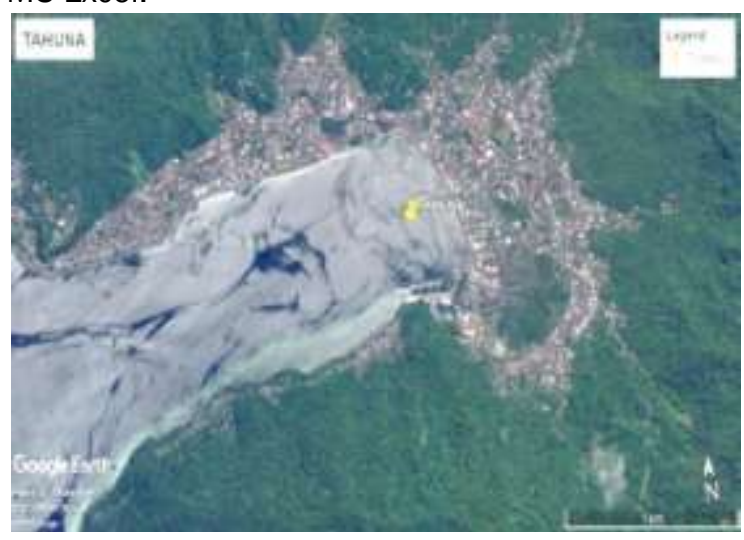

Gambar 3. Tide Gauge didepan Tahuna

Proses pengolahan data pada software TUNAMIN2 untuk mendapatkan nilai ketinggian dan waktu tiba gelombang tsunami ditunjukkan oleh diagram alir berikut.

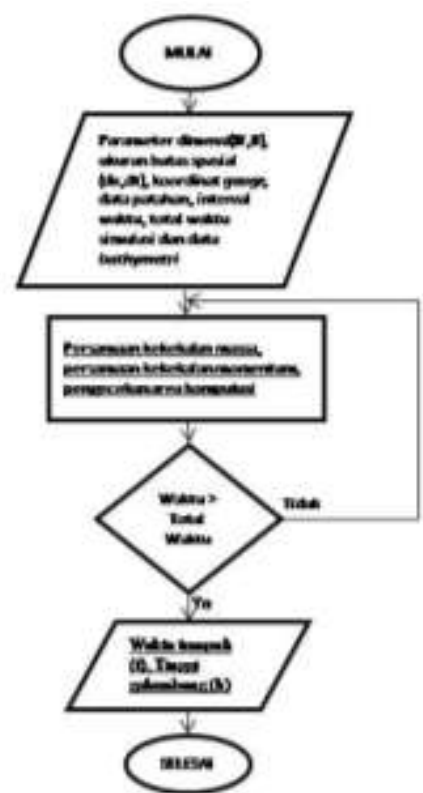

Gambar 4. Diagram Alir Perhitungan TUNAMI-N2 Diagram Alir Penelitian 


\section{Hasil dan Pembahasan}

Proses penjalaran tsunami ditampilkan dalam 3 layer yang masing-masing ditampilkan dalam ukuran peta yang berbeda. Pada gambar 5, dapat dilihat posisi mula-mula dari gelombang tsunami dimana bagian yang berwarna merah adalah gelombang naik dan bagian yang berwarna biru adalah gelombang surut.

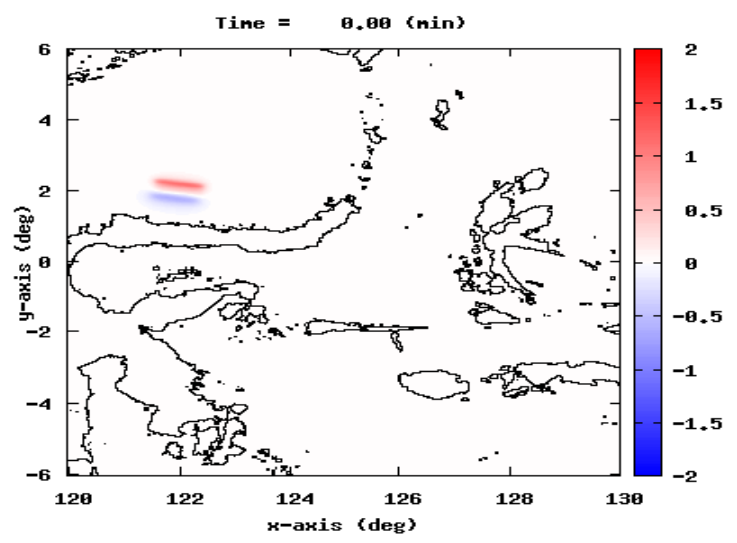

Gambar 5. Pusat Tsunami pada Layer 1

Pada gambar 6 dapat dilihat bahwa gelombang tsunami mencapai Kepulauan Sangihe pada sekitar menit ke-30.

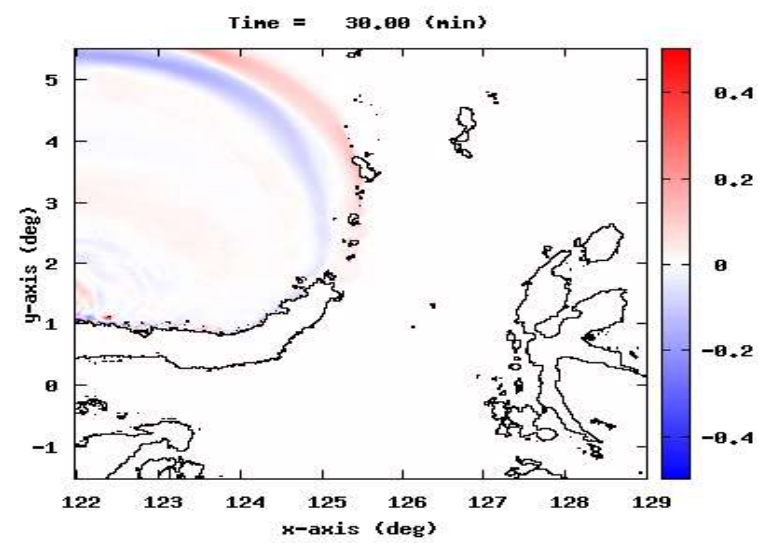

Gambar 6. Tsunami mencapai Kepulauan Sangihe

Pada gambar 7, terlihat semakin jelas penampakan gelombang tsunami yang menerjang Tahuna dimana tsunami yang terjadi didahului oleh gelombang naik bukan gelombang surut.

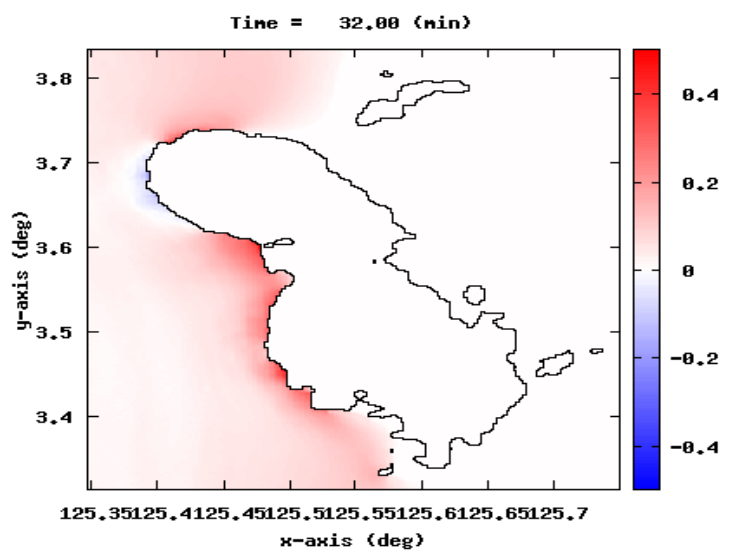

Gambar 7. Gelombang Pasang tiba di Kepulauan Sangihe
Dari gambar 7, terlihat bahwa tsunami tiba pada menit ke-32 untuk sebagian pesisir wilayah Kepulauan Sangihe. Data yang didapat dari tide gauge kemudian diolah kedalam bentuk grafik untuk melihat bentuk gelombang tsunami yang lebih jelas seperti ditunjukkan pada gambar 7 . Berdasarkan data yang didapatkan tsunami terjadi pada detik ke-1.880 dengan ketinggian gelombang $0,003 \mathrm{~m}$ yang kemudian meningkat terus menerus sehingga mencapai ketinggian gelombang tsunami maksimum 0,23 m pada detik ke-3.010 atau sekitar 50 menit kemudian.

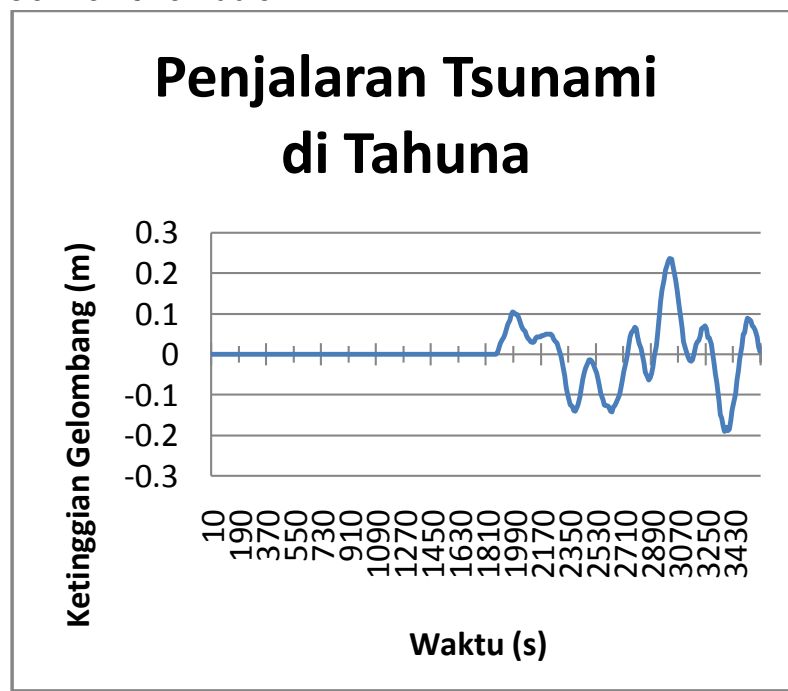

Gambar 8. Grafik Penjalaran Gelombang Tsunami di Tahuna

Dari hasil yang didapat pada gambar 8 , terlihat bahwa gelombang tsunami yang dihasilkan gempa bumi dengan magnitudo $8,0 \mathrm{SR}$ saat menerjang Tahuna menghasilkan gelombang tsunami dengan ketinggian maksimum 0,23 m dengan waktu tiba sekitar 50 menit setelah tsunami dibangkitkan.

Penyebab mengapa tsunami yang dihasilkan tidak terlalu membahayakan diakibatkan jarak Kepulauan Sangihe dengan pusat gempa berjarak cukup jauh yaitu sekitar $460 \mathrm{~km}$. Kemudian, posisi dari Kepulauan Sangihe yang tidak berhadapan secara langsung dengan pusat gempa yaitu pada arah timur laut dari pusat gempa sehingga energi gelombang tsunami tidak terlalu besar.

Selain itu, apabila terjadi gelombang tsunami dengan energi lebih besar yang perlu diwaspadai adalah sifat dari gelombang tsunami yang mengarah ke Kepulauan Sangihe dimana gelombang tsunami tidak akan didahului oleh gelombang surut terlebih dahulu melainkan gelombang pasang. Dengan informasi yang didapatkan dari simulasi ini diharapkan warga lebih waspada terhadap potensi bencana gempa bumi dan tsunami.

\section{Kesimpulan}

Berdasarkan hasil penelitian, maka dapat disimpulkan bahwa apabila gempa bumi dengan magnitudo 8,0 SR terjadi di Laut Sulawesi maka gelombang tsunami dengan ketinggian gelombang 0,23 $\mathrm{m}$ dengan waktu tiba sekitar menit ke-50 
dapat menerjang Tahuna dimana gelombang

tsunami akan didahului dengan gelombang naik.

Daftar Pustaka

Bryant, E. 2014. Tsunami: The Underrated Hazard 3rd Ed. Springer International Publishing, Cham.

Fu, L., M. Heidarzadeh, D. Cukur, F.L. Chiocci, D. Ridente, F. Gross, J. Bialas, dan S. Krastel. 2017. Tsunamigenic Potential of A Newly Discovered Active Fault Zone in the Outer Messina Strait, Southern Italy. Geophys. Res. Lett. 44: 1-9.

Hamzah, L., N.T. Puspito, dan F. Imamura. 2000. Tsunami Catalog and Zones in Indonesia. Journal of Natural Disaster Science. 22(1): 2543.

Heidarzadeh, M. dan K. Satake. 2017. A Combined Earthquake - Landslide Source Model for the Tsunami from the 27 November 1945 Mw 8.1 Makran Earthquake. Bull. Seismol. Soc. Am. 107(2): 1-8.

Imamura, F., A.C. Yalciner, dan G. Ozyurt. 2006. Tsunami Modelling Manual (TUNAMI model). http://www.tsunami.civil.tohoku.ac.jp/hokusai3 /E/projects/manual-ver-3.1.pdf [4 September 2017].

Lovholt, F., D. Kuhn, H. Bungum, C.B. Harbitz, dan S. Glimsdal. 2012. Historical Tsunamis and Present Tsunami Hazard in Eastern Indonesia and the Southern Philippines. Journal of Geophysical Research. 117: 1-19.

Pasau, G dan A. Tanauma. 2011. Pemodelan Sumber Gempa di Wilayah Sulawesi Utara Sebagai Upaya Mitigasi Bencana Gempa Bumi. Jurnal IImiah Sains. 11(2): 202-209.

Prerna, R., T.S. Kumar, R.S. Mahendra, dan P.C. Mohanty. 2014. Assessment of Tsunami Hazard Vulnerability Along the Coastal Environs of Andaman Islands. Nat. Hazards. 1-26.

Pribadi, S., N.T. Puspito, M.S.S. Rahman, dan Trisnawati. 2016. Earthquake Source Characterization for Tsunami Zoning (Case Study of the Bengkulu 12 September 2007 Tsunami and 2 June 1994 Banyuwangi Tsunami). AIP Conf. Proc. 1730: 1-14.

Selvan, S.C. dan R.S. Kankara. 2016. Tsunami Model Simulation for 26 December 2004 and Its Effect on Koodankulam Region of Tamil Nadu Coast. International Journal of Ocean and Climate Systems. 7(2): 62-69.

Wells, D.L. dan K.J. Coppersmith. 1994. New Empirical Relationship among Magnitudo, Rupture Length, Rupture Width, Rupture Area, and Surface Displacement. Bull. Seismol. Soc. Am. 84(4): 974-1002. 